\title{
Identification of cryptic species and morphotypes in male Euglossa : morphometric analysis of forewings (Hymenoptera: Euglossini)
}

\author{
J. J. G. QueZada-EuÁn ${ }^{1}$, H. D. Sheets ${ }^{2}$, E. De Luna ${ }^{3}$, T. Eltz ${ }^{4}$ \\ ${ }^{1}$ Departamento de Apicultura Tropical- Campus Ciencias Biológicas y Agropecuarias, Universidad Autónoma de \\ Yucatán, Mérida, Mexico \\ ${ }^{2}$ Canisius College, Buffalo, NY, USA \\ ${ }^{3}$ Biodiversidad y Sistemática, INECOL, Xalapa, Mexico \\ ${ }^{4}$ Department of Animal Ecology, Evolution and Biodiversity, Ruhr-Universität, Bochum, Germany
}

Received 3 February 2015 - Revised 10 April 2015 - Accepted 17 April 2015

\begin{abstract}
Males of sibling orchid bees Euglossa viridissima and Euglossa dilemma are morphologically cryptic, except for the number and shape of mandibular teeth. An alternative morph of E. viridissima has a third tooth similar to males of $E$. dilemma. We used this model system to evaluate the potential of wing morphometrics for the resolution of these groups. We found differences in the size characters of forewings of E. viridissima and E. dilemma albeit with substantial overlapping amongst them. However, geometric morphometrics of forewing vein intersections separated both species and, to a lesser extent, morphotypes. A discriminant analysis of the shape of the radial cell showed separation between all three groups, too, albeit with higher misclassification between $E$. viridissima and E. dilemma. We show that sibling cryptic species and morphotypes can be identified by geometric morphometrics, supporting its application with other methods as powerful aids to infrageneric taxonomy in bees.
\end{abstract}

orchid bee / cryptic species / morphotypes / geometric morphometrics / forewing

\section{INTRODUCTION}

Euglossines, commonly called orchid bees (Hymenoptera, Apidae, Euglossini) are neotropical, iridescent colored insects, well known for the males' behavior of collecting volatiles from orchids and other sources (Dressler 1982). Euglossa Letreille is the largest genus of orchid bees with over 100 described species (Roubik and Hanson 2004).

Electronic supplementary material The online version of this article (doi:10.1007/s13592-015-0369-7) contains supplementary material, which is available to authorized users.

Corresponding author: J. Quezada-Euán, qeuan@uady.mx

Manuscript editor: Klaus Hartfelder
The taxonomy of Euglossini is mostly based on the analysis of male traits (Roubik and Hanson 2004). Detailed morphological revisions of male Euglossini have resulted in the discovery of several sibling and cryptic species (Oliveira and Nemésio 2003; Ramírez 2006; Rasmussen and Skov 2006; Nemésio and Bembé 2008; Hinojosa-Díaz et al. 2011, 2012; Nemésio and Engel 2012). These types of revisions can make use of the additional information obtained from morphometric multivariate methods and molecular plus biochemical tools (Eltz et al. 2011; Pokorny et al. 2014).

Insect wing morphometrics has been shown to be a quick and inexpensive method that provides reliable resolution on the specific and infraspecific levels of various taxa (Ruttner 1988; Haas and Tolley 1998; Klingenberg et al. 2001; 
Dujardin et al. 2003). Recently, geometric morphometric approaches have shown higher statistical power compared to traditional morphometrics for species separation (Bookstein 1991; Zelditch et al. 2004; Francoy et al. 2011; Zinetti et al. 2013). By eliminating the effect of size, statistical comparison of landmarks used in geometric morphometrics can reveal differences of actual shapes or forms with greater power of discrimination (Mitteroecker and Gunz 2009). In bees, geometric morphometrics of the forewing has been capable of discriminating operational taxonomic units (Aytekin et al. 2007; Francoy et al. 2008, 2011; Kandemir et al. 2011). Importantly, such identification seems to conform to those based on molecular markers (Francoy et al. 2012; Oleksa and Tofilski 2015). However, in bees, the use of geometric morphometrics for the discrimination of cryptic species has remained uninvestigated, in spite of its promising use in other insect taxa (Baylac et al. 2003; Pizzo et al. 2006; GurgelGoncalves et al. 2011; Muñoz-Muñoz et al. 2011; Mitrovski-Bogdanović et al. 2013). Overall, the application of geometric morphometrics to assess intraspecific morphological differentiation and intra-sexual plasticity is still a largely unexplored field in bees (Danforth and Desjardins 1999).

In this respect, male orchid bees of sibling Euglossa viridissima Friese and Euglossa dilemma Bembé and Eltz represent a unique model for evaluating geometric morphometric methods in the identification of cryptic species and morphotypes altogether. The E. viridissima-E. dilemma species pair exists in sympatry in the Tehuantepec Isthmus and the Yucatan Peninsula of Mexico (Eltz et al. 2011). Morphometric methods based on measures of body size have failed to separate sibling E. viridissima and E. dilemma males which remain cryptic for several characters traditionally used in bee morphometrics (Ramirez-Pech 2009). So far, males of both species can only be separated phenotypically by their number and shape of mandibular teeth. Males of E. viridissima are commonly bidentate $(2 \mathrm{D},>90 \%$ of individuals) but occasionally tridentate (3D) with the middle dentition near the distal one, whereas E. dilemma are always tridentate with the middle dentition placed centrally (Eltz et al. 2011). Females of both species are superficially identical and can only be separated by molecular markers (Eltz et al. 2011; May-Itzá et al. 2014). Male 2D and 3D E. viridissima are chemically and genetically indistinguishable (Eltz et al. 2011; Pokorny et al. 2014; Ramírez et al., unpublished data). Moreover, both male types emerge from clutches of the same mother (T. Eltz and Quezada-Euán, unpublished data), confirming that they are in fact individuals of the same species.

In this study, we evaluated the power of wing morphometrics for identifying cryptic species and species morphotypes in bees using as a model the E. viridissima-E.dilemma species complex. Both traditional morphometrics based on wing size (traditional morphometrics) and geometric morphometrics of shape were included in the study.

\section{MATERIALS AND METHODS}

\subsection{Material collection}

Males of E. viridissima and E. dilemma were collected in 13 localities across the Yucatan Peninsula during 2010 using synthetic benzyl benzoate (BB), 1,8-cineole (C), eugenol (E), methyl salicylate (MS), p-dimethoxybenzene (PDMB), and methyl cinnamate (TMC) as baiting substances (Pokorny et al. 2013). Individuals were kept in ethanol and stored at $-20^{\circ} \mathrm{C}$ awaiting further analyses. Males were separated into E. dilemma and E. viridissima and the two morphs in the latter in accordance to the number of mandibular teeth and their position. For all statistical analyses, the three a priori groups consist of $442 \mathrm{D}$ and $233 \mathrm{D}$ specimens of E. viridissima, and 41 of E. dilemma were identified.

\subsection{Preparation of forewings}

From each specimen, the right forewing was dissected from the base of the radial vein with the help of forceps and mounted between glass slides to keep them flat. Wings were photographed using an OpticFilm 7200 scanner (Plustek) for diapositives at 3600 dpi. We used $28 \times 48 \mathrm{~mm}, 1.55-\mathrm{mm}$ thickness microscope slides to sandwich wings, which fitted the slide scanner. 


\subsection{Analyses of size}

For the analyses of size, we used distances and angles formed by vein intersections. We first recorded 18 landmarks of the intersections of the veins on the right forewing (Figure 1). Cartesian coordinates of points on the photograph of the forewing of each individual male were registered using the software tpsDig2 version 2.12 (Rohlf 2008). After this, all configurations were aligned using Procrustes superimposition by means of the software CoordGen6 (Sheets 2006).

Ten inter-landmark distances and seven angles between vein intersections were then calculated using the program TMorphGen (Sheets 2006) generating a set of "traditional" morphometric measurements.

A general measure of forewing size for each specimen was also obtained using the values of the centroid size for the distances between vein intersections calculated by CoordGen6. The distances and angles formed by forewing venation landmarks used in the analyses are shown in Table I.

The mean values for each distance between vein intersections, centroids, and angles were compared between the three male types by means of ANOVA. Multiple comparisons were conducted by means of a Duncan's range test. After this, we could identify which characters showed differences between groups. In a further step, we used the forewing traits that showed significant differences between groups in a multivariate approach by means of a principal components analysis (PCA).

Three principal components were obtained with their associated eigenvalues. These were used to calculate the percentage variation explained by each component. Scores for each male for each component were calculated using the coefficients assigned to each individual variable. To test for overall size differences between individuals of the three groups, the resulting scores were compared by means of ANOVA. Comparisons between

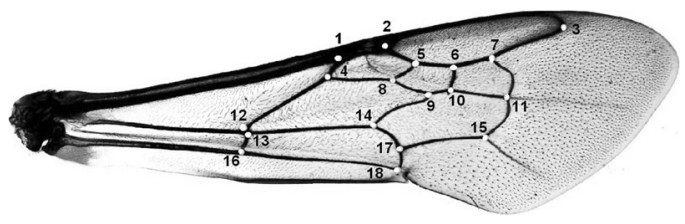

Figure 1. Landmarks of forewing vein intersections used in the analyses of size and shape of males of Euglossa dilemma and Euglossa viridissima morphs.
Table I. Distances and angles formed by venation landmarks used in the analyses of forewing size and shape.

\begin{tabular}{llll}
\hline $\begin{array}{l}\text { Distances } \\
\text { between vein } \\
\text { intersections }\end{array}$ & $\begin{array}{l}\text { Landmark } \\
1\end{array}$ & $\begin{array}{l}\text { Landmark } \\
2\end{array}$ & $\begin{array}{l}\text { Landmark } \\
\text { 3 (angle } \\
\text { intersect) }\end{array}$ \\
\hline 1 & 13 & 14 & - \\
2 & 1 & 13 & - \\
3 & 11 & 15 & - \\
4 & 12 & 16 & - \\
5 & 8 & 16 & - \\
6 & 10 & 12 & - \\
7 & 3 & 9 & - \\
8 & 7 & 18 & - \\
9 & 3 & 5 & - \\
10 & 6 & 18 & - \\
Angles & & & \\
1 & 7 & 15 & 16 \\
2 & 6 & 7 & 18 \\
3 & 12 & 14 & 15 \\
4 & 4 & 8 & 5 \\
5 & 8 & 11 & 12 \\
6 & 10 & 13 & 1 \\
7 & 2 & 3 & 9 \\
\hline
\end{tabular}

male types were conducted by means of Duncan's multiple range tests. The PC scores were plotted on a bidimensional scale using PC1 and PC2 which represent the largest amount of variation in the data.

\subsection{Analyses of shape}

The same 18 landmarks (vein intersections), as in Figure 1 were used for the analysis of the shape of forewing venation pattern. Additionally, we also analyzed the shape of the radial cell in 28 males of each, 2D E. viridissima and E. dilemma, plus ten males of 3D E. viridissima. We analyzed the radial cell because it has been shown to accurately separate races of Apis mellifera (Francoy et al. 2006). For the analysis of radial cell shape, we used semilandmarks (points not anatomically defined on the structure) as it has a curvilinear shape (Figure 2). To define the contour of the radial cell, we used 18 semilandmarks produced between landmarks 1 and 13 in the radial cell (Figure 1) using the option "comb" of the program MakeFan6 (Sheets 2006). 


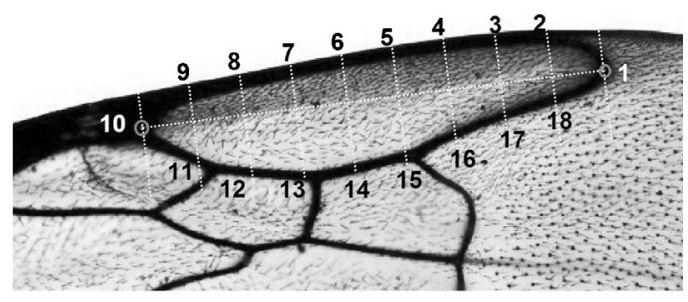

Figure 2. Semilandmarks used in the analyses of shape of radial cell of males of Euglossa dilemma and Euglossa viridissima morphs. The numbers 1 and 10 indicate real landmarks from which equidistant points were defined around the cell contour.

The landmarks and semilandmarks were submitted to canonical variates analyses to evaluate the relative power of discrimination of the pattern of forewing venation and radial cell shapes, respectively. The analyses were based on partial warp scores on the Procrustes superimposed images using the CVAGen software (Sheets 2006). We calculated the number of significant CVA axes at $P=0.05$ and, afterwards, computed the canonical variates scores of individual males. Additionally, we used Mahalanobis distances to assign all the specimens to one of the three groups loaded. The CVA scores for each individual of the three types of male were compared by means of ANOVA. We performed jackknifed assignments of the specimens in order to test the accuracy of the CVA scores in establishing differences between male types. Finally, the CVA scores were plotted on a bidimensional scale against the Canonical variates 1 and 2 to detect group differences in shape.

\section{RESULTS}

\subsection{Analyses of size}

The comparison of size between species and morphs was based on the vein intersection distances, centroids, and angles of the forewing (traditional morphometric measures) at univariate and multivariate levels. The results of ANOVA to compare male types at the univariate level are presented in Supplementary Table 1.

The statistics of PCA using distances between forewing vein intersections are presented in Supplementary Tables 2-4.

The Kaiser's measure of sampling adequacy was 0.874 which indicated that the correlation matrix was adequate for PCA. The first two components included $84 \%$ of the total variation (76.7 \% for PC1 and $7.4 \%$ for PC2, respectively). PC1 was positively correlated with the 13 distances between vein intersection of the forewing (Supplementary Table 1) probably indicating that PC1 is largely an overall size measure. The mean score values for $\mathrm{PC} 1$ were significantly different between the three male types $(F=36.05 ; d f=2$, $107 ; P=0.001$; Table II). The results of Duncan's multiple range test showed that the mean of the PC1 scores of 2D and 3D E. viridissima males were not significantly different from each other ( 0.531 and 0.428 , respectively) but that they differed from those of E. dilemma $(-0.810)$. This means that distances between forewing intersections are smaller in males of E. dilemma compared with both morphotypes of E. viridissima . For both PC2 and PC3, there were no significant differences between the scores of the three groups $(F=2.7 ; d f=2,107 ; P=0.07$ and $F=0.37 ; d f=2$, $107 ; P=0.69$, respectively; Table II).

The individual scores were plotted against PC1 and PC2 (Figure 3). The distribution of both morphotypes of $E$. viridissima is evident towards the right of PC1 compared with E. dilemma confirming the smaller size of these individuals for these characters. However, in spite of statistical differences of size between E. viridissima and E. dilemma along PC1, some individuals overlapped, especially the 3D morph with the latter. Nevertheless, individuals of both E. viridissima morphotypes substantially overlapped along this component (Figure 3). Similarly, overlapping of both species and morphotypes was evident along PC2. This result is consistent with the ANOVA results, indicating a difference in the means relative to within group variance but does indicate substantial overlap of the individuals along these variables.

\subsection{Analyses of shape}

The results of the analyses of shape of the pattern of forewing venation by MANOVA indicated statistical differences amongst the three male types (Wilk's $\lambda=0.001 ; P<0.001$ ). Two canonical variates showed significant differences between groups (axis $1 \lambda=0.551$, chisq $=61.97$, 
Table II. Comparison of mean of scores for males of Euglossa dilemma and Euglossa viridissima morphs for each of the three principal components derived from forewing distances between vein intersections.

\begin{tabular}{llllll}
\hline & \multicolumn{2}{l}{ Male type } & \multirow{2}{*}{$F$ value } & Prob. $F$ \\
\cline { 2 - 4 } & E. viridissima $2 \mathrm{D}$ & E. viridissima $3 \mathrm{D}$ & E. dilemma & & \\
\hline PC 1 & $0.531 \mathrm{a}(0.117)$ & $0.428 \mathrm{a}(0.162)$ & $-0.810 \mathrm{~b}(0.121)$ & 36.05 & 0.001 \\
PC 2 & $0.147(0.148)$ & $0.215(0.205)$ & $-0.279(0.153)$ & 2.70 & 0.072 \\
PC 3 & $0.045(0.151)$ & $0.096(0.209)$ & $-0.103(0.157)$ & 0.37 & 0.692 \\
\hline
\end{tabular}

Standard deviations are presented in brackets

$d f=6, P=0.001$ and axis $2 \lambda==0.865$, chisq=15.03, $d f=2, P=0.001)$. Since there were three groups of specimens in the study, there could be a maximum of two statistically significant axes, as occurred here.

The ANOVA of CVA scores revealed significant differences for CV1 $(F=118.39 ; d f=2,107$; $P=0.001$; Table III) between the means of E. dilemma (20.42) and the two morphs of E. viridissima but not between the latter two ( -9.35 for $3 \mathrm{D}$ and -14.13 for $2 \mathrm{D}$ ones). Significant differences were also found for CV2 scores $(\mathrm{F}=25.64 ; d f=2,107 ; P=0.001)$. The means of E. viridissima 3D morph (20.21) differed from the 2D morph and E. dilemma which were not significantly different amongst them $(-8.12$ and -14.39 , respectively) (Table III).

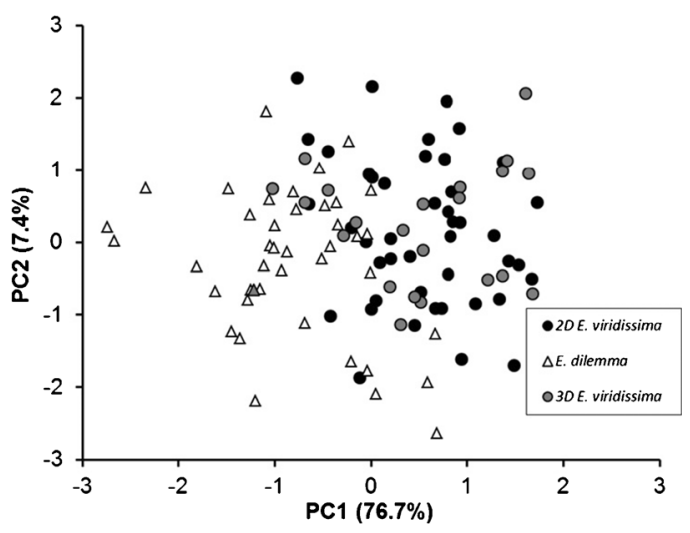

Figure 3. Plot of individual scores of males of Euglossa dilemma and Euglossa viridissima morphs against principal components 1 (PC1) and 2 (PC2) from the analysis of distances between forewing vein intersections. The percentage of variation explained by each component is presented in brackets.
A jackknifed assignment test showed that $96 \%$ of the E. dilemma specimens were correctly assigned to their group, while the rest were incorrectly assigned to E. viridissima $3 \mathrm{D}(4 \%)$. In the case of E. viridissima $2 \mathrm{D}$ and $3 \mathrm{D}, 4 \%$ were incorrectly assigned to E. dilemma, respectively. More incorrect assignments occurred between 2D and $3 \mathrm{D}$ E. viridissima. In the case of $2 \mathrm{D}$ males, $34 \%$ were incorrectly assigned to the $3 \mathrm{D}$ morphotype and in the case of the latter, $43 \%$ were incorrectly assigned to the 2D morphotype. The plot of the distribution of the scores against canonical variates 1 and 2 is presented in Figure 4. A clear separation between E. dilemma and the two $E$. viridissima morphos is evident against CV1 compared with a higher overlap between the latter two. Overlapping of the three groups is also evident along CV2.

Statistical differences amongst the three male types was also evident with the analysis of shape of the radial cell (MANOVA Wilk's $\lambda=0.001 ; P<0.001)$. Two canonical variates showed significant differences between groups (axis $1 \quad \lambda=0.4407$; chisq $=50.801$; $d f=6 ; \quad P=0.001$ and axis $2 \lambda==0.718$; chisq=20.468; $d f=2 ; P=0.001$ ).

The ANOVA of CVA scores revealed significant differences for CV1 $(F=19.46 ; d f=2,65$; $P=0.001$; Table III). The mean of the E. viridissima $2 \mathrm{D}$ morph (0.336) was different from both, the $3 \mathrm{D}$ morph $(-0.230)$ and E. dilemma $(-0.243)$ that were not different between each other. Significant differences were also found for CV2 scores $(F=14.53 ; d f=2,107$; $P=0.001)$. The means of the $E$. viridissima $3 \mathrm{D}$ morph $(-0.628)$ differed from the 2D morph and E. dilemma which were not significantly different 
Table III. Comparison of means of CVA scores of males of Euglossa dilemma and Euglossa viridissima morphs for landmarks of forewing venation and semilandmarks of radial cell.

\begin{tabular}{lcccrc}
\hline \multirow{2}{*}{ Forewing venation landmarks } & \multicolumn{1}{l}{ Male type } & & \multirow{2}{*}{$F$ value } & \multirow{2}{*}{ Prob. $F$} \\
\cline { 2 - 4 } & E. viridissima 2D & E. viridissima 3D & E. dilemma & & \\
\hline CV1 & $-14.13 \mathrm{a}(1.65)$ & $-9.35 \mathrm{a}(2.41)$ & $20.42 \mathrm{~b}(1.22)$ & 118.39 & $<0.001$ \\
CV2 & $-8.12 \mathrm{a}(3.22)$ & $20.21 \mathrm{~b}(2.32)$ & $-14.39 \mathrm{a}(2.47)$ & 25.64 & $<0.001$ \\
Radial cell semilandmarks & & & & & \\
CV1 & $0.336 \mathrm{a}(0.07)$ & $-0.230 \mathrm{~b}(0.11)$ & $-0.243 \mathrm{~b}(0.07)$ & 19.46 & $<0.001$ \\
CV2 & $-0.005 \mathrm{a}(0.08)$ & $-0.628 \mathrm{~b}(0.13)$ & $0.215 \mathrm{a}(0.08)$ & 14.53 & $<0.001$ \\
\hline
\end{tabular}

Standard deviations are presented in brackets

amongst them ( -0.005 and $0.215 \pm 2.4$, respectively).

A jackknifed assignment test showed that $67.8 \%$ of the E. dilemma specimens were correctly assigned to their group, $11 \%$ to E. viridissima $3 \mathrm{D}$ and $21.4 \%$ to $E$. viridissima $2 \mathrm{D}$. In the case of E. viridissima $2 \mathrm{D}$ and $3 \mathrm{D}, 11$ and $10 \%$ were incorrectly assigned to E. dilemma, respectively. In the case of E. viridissima 2D males, $11 \%$ was incorrectly assigned to the 3D morphotype and in the case of the latter, $0 \%$ was incorrectly assigned to the $2 \mathrm{D}$ morphotype. The plot of the distribution of the scores against canonical variates 1 and 2 is presented in Figure 5. A complete overlap along CV1 exists between E. dilemma and 3D E. viridissima . However, a separation is observed between

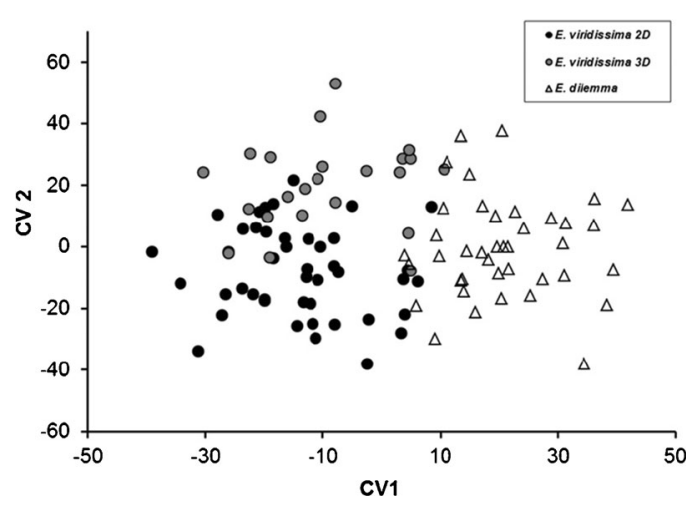

Figure 4. Plot of individual scores of males Euglossa dilemma and Euglossa viridissima morphs against canonical variates 1 (CV1) and 2 (CV2) from the analysis of landmark pattern of forewing venation.
E. dilemma and 2D E. viridissima along the same CV1. Moreover, a degree of separation is observed between the two E. viridissima morphotypes along both CV1 and CV2.

\section{DISCUSSION}

The additional morphometric information used in our study reinforces the identity of $E$ viridissima and $E$. dilemma as separate species (Eltz et al. 2011). Moreover, characters of size and shape of the forewing were capable of separating both morphotypes within E. viridissima. However, it was evident that the degree of separation and its associated significance depended on the type of forewing character used.

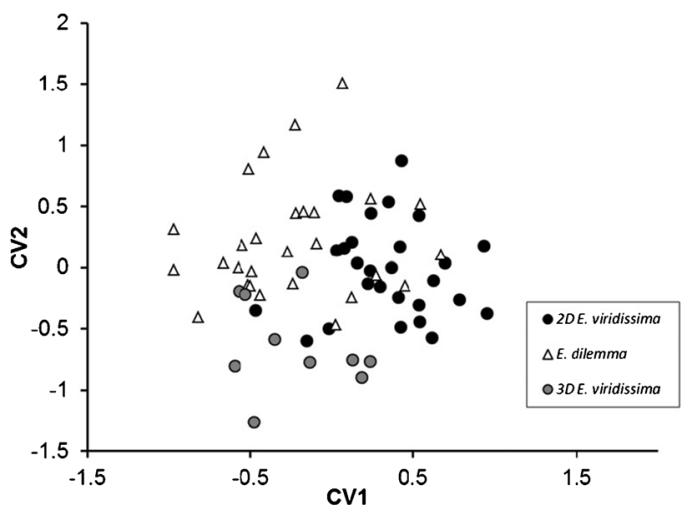

Figure 5. Plot of individual scores of males of Euglossa dilemma and Euglossa viridissima morphs against canonical variates 1 (CV1) and 2 (CV2) from the analysis of semilandmark pattern of the forewing radial cell. 
Overall, characters related to forewing size showed differentiation between species but not morphotypes, whereas characters related to the shape of wing cells varied also between morphotypes within species. In a former study, using various anatomical characters, E. viridissima and E. dilemma showed no differences in an overall estimation of size (RamirezPech 2009; Eltz et al. 2011). However, in this recent approach including a more detailed analysis of forewing vein intersections, both species showed morphological differentiation in this structure. Within the characters that we used to compare size, the angles between vein intersections did not show substantial differences neither between species nor morphotypes. On the other hand, all distances between vein intersections showed significant differences between male species.

In the analyses of shape, the best discriminator between species was the whole pattern on forewing venation that reported the highest level of separation and the lowest percentage of misclassification between species. The semilandmarks associated with the shape of the radial cell showed separation amongst the three groups, albeit with higher misclassification rates between species. These findings suggest that better classification of cryptic species is expected when the shape of the whole pattern of forewing venation is analyzed compared with individual cells.

Our results support to extending the use of forewing geometric morphometrics as a powerful tool for the identification, not only of close bee lineages but of sibling cryptic species and morphotypes within species too. The sensitivity of the method was capable of revealing differences between 2D and 3D E. viridissima. These males have, until now, only been identified by their number of mandibular teeth, but here we show that other features in their anatomy are also substantially different. Highly variable DNA markers (Microsatellites, SNPs) as well as chemical characters (perfumes, cuticular hydrocarbons) are clearly different between E. dilemma and E. viridissima but show no systematic variation amongst $3 \mathrm{D}$ and $2 \mathrm{D}$ males of the latter, confirming that they are in fact polymorphic individuals of the same species (Eltz et al. 2011;
Pokorny et al. 2014; Ramirez et al. unpublished data).

Polymorphism is widely present in insects. It can be produced by alternative genotypes or may be the genotype response to variation in the environment (Fordyce 2006). To date, only a few studies have documented in detail the extent of intra-sexual plasticity in the social Hymenoptera (ants, bees, and wasps) and they have been mostly conducted on females (but see Danforth and Desjardins 1999). The physiological basis of male wing polymorphism in bees, thus, is not clearly understood. In other insect taxa, male wing polymorphism can result from variation in both genetic and environmental factors (Zera 2004). Ultimately, hormonal differences, particularly in the titer of juvenile hormone during the last juvenile instars might explain the development of different morphs (Zera 2004). It has also been shown that the development of wings involves numerous genes that act from egg to adulthood, so stresses that act at different times could alter their shape in specific ways (Hoffmann et al. 2005). Similarly, the observed wing shape differences between 2D and $3 \mathrm{D}$ E. viridissima males could be the result of stressful conditions during their development, although both morphs seem to persist across time and space (Eltz and Quezada-Euán unpublished data) possibly indicating little effect of environmental constraints (see Simmons et al. 2000).

Our results on forewing morphology of 2D and 3D E. viridissima males indicate that polymorphism apparently extends to traits of their anatomy other than dentition. Several selective mechanisms may explain the maintenance of polymorphisms within a species. Disruptive selection and heterozygote advantage are likely to play important roles but the most common explanation is frequency-dependent selection (Ajuria-Ibarra and Reader 2013). It would be daring to suggest a mechanism for the maintenance of $2 \mathrm{D}$ and $3 \mathrm{D}$ males in E. viridissima. It is therefore important to understand the mechanism(s) that preserve both morphotypes to help explain how genetic diversity is maintained within these populations and the evolutionary biology of orchid bees.

Due to their particular mode of sexual attraction, seemly based on non-visual mating signals (chemical display by males; Eltz et al. 2005), 
species of euglossines could have diverged without substantial changes in morphology and meristic characters (Eltz et al. 2008), thus remaining cryptic under traditional alpha taxonomy (Bickford et al. 2007). In this respect, geometric morphometrics data can be of much help in the taxonomic revision of euglossines.

\section{ACKNOWLEDGMENTS}

We would like to thank projects Conacyt 103341 "Identificación de especies crípticas e indicadores de diversidad genética en abejas nativas de México" and DAAD-Proalmex B330/336/11 "Divergencia en linajes de Euglossa (Hymenoptera: Euglossini) en relación con la disponibilidad de fragancias a lo largo de una clina ecológica en la Península de Yucatán" for the financial support.

Identification d'espèces cryptiques et morphotypes chez des mâles d'Euglossa: analyse morphométrique des ailes antérieures (Hymenoptera: Euglossini)

abeille à orchidée / morphométrie géométrique / aile / espèce jumelle

Identifizierung kryptischer Arten und von Morphospezies in Euglossa-Männchen: Morphometrische Analyse der Vorderflügel (Hymenoptera: Euglossini)

Prachtbienen / kryptische Arten / Morphotypen / geometrische Morphometrie / Vorderflügel

\section{REFERENCES}

Ajuria-Ibarra, H., Reader, T. (2013) Reasons to be different: do conspicuous polymorphisms in invertebrates persist because rare forms are fitter? J. Zool. 290, 81-95

Aytekin, A.M., Terzo, M., Rasmont, P., Çagatay, N. (2007) Landmark based geometric morphometric analysis of wing shape in Sibiricobombus Vogt (Hymenoptera: Apidae: Bombus Latreille). Ann. Soc. Entomol. Fr. (n.s.) 43, 95-102

Baylac, M., Villemant, C., Simbolotti, G. (2003) Combining geometric morphometrics with pattern recognition for the investigation of species complexes. Biol. J. Linn. Soc. 80, 89-98

Bickford, D., Lohman, D.J., Sodhi, N.S., Ng, P.K.L., Meier, R., Winker, K., Ingram, K.K., Das, I. (2007) Cryptic species as a window on diversity and conservation. Trends Ecol. Evol. 22, 148-155
Bookstein, F.L. (1991) Morphometric Tools for Landmark Data: Geometry and Biology. Cambridge University Press, Cambridge

Danforth, B.N., Desjardins, C.A. (1999) Male dimorphism in Perdita portalis (Hymenoptera, Andrenidae) has arisen from preexisting allometric patterns. Insect. Soc. 46, 18-28

de J May-Itzá, W., Medina-Medina, L.A., Medina, S., Paxton, R.J., Quezada-Euán, J.J.G. (2014) Seasonal nest characteristics of a facultatively social orchid bee, Euglossa viridissima, in the Yucatan Peninsula, Mexico. Insect. Soc. 61, 183-190

Dressler, R.L. (1982) Biology of the orchid bees (Euglossini). Annu. Rev. Ecol. Syst. 13, 373-394

Dujardin, J.P., Le Pont, F., Baylac, M. (2003) Geographic versus interspecific differentiation in sand flies: a landmark data analysis. Bull. Entomol. Res. 93 , 87-90

Eltz, T., Sager, A., Lunau, K. (2005) Juggling with volatiles: exposure of perfumes by displaying male orchid bees. J. Comp. Physiol. A. 191, 575-581

Eltz, T., Zimmermann, Y., Pfeiffer, C., Ramírez Pech, J., Twele, R., Francke, W., Quezada-Euán, J.J.G., Lunau, K. (2008) An olfactory shift is associated with male perfume differentiation and species divergence in orchid bees. Curr. Biol. 18, 1844-1848

Eltz, T., Fritzsch, F., Ramírez Pech, J., Zimmermann, Y., Ramírez, S.R., Quezada-Euán, J.J.G., Bembé, B. (2011) Characterization of the orchid bee Euglossa viridissima (Apidae: Euglossini) and a novel cryptic sibling species, by morphological, chemical, and genetic characters. Zool. J. Linn. Soc. 163, 1064-1076

Fordyce, J.A. (2006) The evolutionary significance of ecological interactions mediated through phenotypic plasticity. J. Exp. Biol. 209, 2377-2383

Francoy, T.M., Prado, P.R.R., Gonçalves, L.S., Da Fontoura Costa, L., De Jong, D. (2006) Morphometric differences in a single wing cell can discriminate Apis mellifera racial types. Apidologie 37, 91-97.

Francoy, T.M., Wittmann, D., Drauschke, M., Müller, S., Steinhage, V., Bezerra-Laure, M.A.F., De Jong, D., Gonçalves, L.S. (2008) Identification of Africanized honey bees through wing morphometrics: two fast and efficient procedures. Apidologie 39, 488-494

Francoy, T.M., Grassi, M.L., Imperatriz-Fonseca, V.L., de J May-Itzá, W., Quezada-Euán, J.J.G. (2011) Geometric morphometrics of the wing as a tool for assigning genetic lineages and geographic origin in Melipona beecheii (Hymenoptera:Meliponini). Apidologie 42, 499-507

Francoy, T.M., Franco, F.F., Roubik, D.W. (2012) Integrated landmark and outline-based morphometric methods efficiently distinguish species of Euglossa (Hymenoptera, Apidae, Euglossini). Apidologie 43, 609-617

Gurgel-Goncalves, R., Ferreira, J.B.C., Rosa, A.F., Bar, M.E., Galvao, C. (2011) Geometric morphometrics and ecological niche modelling for delimitation of near-sibling triatomine species. Med. Vet. Entomol. 25, 84-93 
Haas, H.L., Tolley, K.A. (1998) Geographic variation of wing morphology in three Eurasian populations of the fruit fly, Drosophila lummei . J. Zool. (Lond.) 245, 197-203

Hinojosa-Díaz, I.A., Melo, G.A.R., Engel, M.S. (2011) Euglossa obrima, a new species of orchid bee from Mesoamerica, with notes on the subgenus Dasystilbe Dressler (Hymenoptera, Apidae). ZooKeys 97, 11-29

Hinojosa-Diaz, I.A., Nemesio, A., Engel, M.S. (2012) Two new species of Euglossa from South America, with notes on their taxonomic affinities (Hymenoptera, Apidae). Zookeys 221, 63-79

Hoffmann, A.A., Woods, R.E., Collins, E., Wallin, K., White, A., McKenzie, J.A. (2005) Wing shape versus asymmetry as an indicator of changing environmental conditions in insects. Aust. J. Entomol. 44, 233-243

Kandemir, I., Özkan, A., Fuchs, S. (2011) Reevaluation of honey bee (Apis mellifera) microtaxonomy: a geometric morphometric approach. Apidologie 42, 618-627

Klingenberg, C.P., Badyaev, A.V., Sowry, S.M., Beckwith, N.J. (2001) Inferring developmental modularity from morphological integration: analysis of individual variation and asymmetry in bumblebee wings. Am. Nat. 157, 11-23

Mitrovski-Bogdanović, A., Petrović, A., Mitrović, M., Ivanović, A., Žikić, V., Starý, P., Vorburger, C., Tomanović, Z. (2013) Identification of two cryptic species within the Praon abjectum Group (Hymenoptera: Braconidae: Aphidiinae) using molecular markers and geometric morphometrics. Ann. Entom. Soc. Am. 106, $170-180$

Mitteroecker, P., Gunz, P. (2009) Advances in geometric morphometrics. Evol. Biol. 36, 235-247

Muñoz-Muñoz, F., Talavera, S., Pagès, N. (2011) Geometric morphometrics of the wing in the subgenus Culicoides (Diptera: Ceratopogonidae): from practical implications to evolutionary interpretations. J. Med. Entomol. 48, 129-139

Nemésio, A., Bembé, B. (2008) A new species of Eufriesea from Bolivia, and rearrangement of the Eufriesea auripes species group (Hymenoptera: Apidae). Spixiana 31, 241-246

Nemésio, A., Engel, M.S. (2012) Three new cryptic species of Euglossa from Brazil (Hymenoptera, Apidae). Zookeys 222, 47-68

Oleksa, A., Tofilski, A. (2015) Wing geometric morphometrics and microsatellite analysis provide similar discrimination of honey bee subspecies. Apidologie 46, 49-60

Oliveira, M.L., Nemésio, A. (2003) Exaerete lepeletieri (Hymenoptera: Apidae: Apini: Euglossina): a new species of cleptoparasitic bee from Amazonia. Lundiana 4, 117-120
Pizzo, A., Mercurio, D., Palestrini, C., Roggero, A., Rolando, A. (2006) Male differentiation patterns in two polyphenic sister species of the genus Onthophagus Latreille, 1802 (Coleoptera: Scarabaeidae): a geometric morphometric approach. J. Zool. Syst. Evol. Res. 44, 56-62

Pokorny, T., Hannibal, M., Quezada-Euán, J.J.G., Hedenström, E., Sjöberg, J., Bång, J., Eltz, T. (2013) Acquisition of species-specific perfume blends: influence of habitat-dependent compound availability on odour choices of male orchid bees (Euglossa spp.). Oecologia 172, 417-425

Pokorny, T., Lunau, K., Quezada-Euán, J.J.G., Eltz, T. (2014) Cuticular hydrocarbons distinguish cryptic sibling species in Euglossa orchid bees. Apidologie 45, 276-283

Ramírez, S. (2006) Euglossa samperi n. sp., a new species of orchid bee from the Ecuadorian Andes (Hymenoptera:Apidae). Zootaxa 1272, 61-68

Ramirez-Pech, J. (2009) Variación morfométrica y preferencia de fragancias de dos morfotipos machos de Euglossa viridissima en la Península de Yucatán. M. Sc. Thesis Universidad Autónoma de Yucatán, México

Rasmussen, C., Skov, C. (2006) Description of a new species of Euglossa (Hymenoptera: Apidae: Euglossini) with notes on comparative biology. Zootaxa 1210, 53-67

Rohlf, F.J. (2008) tpsDig, version 2.12. Department of Ecology and Evolution, State University of New York, Stony Brook

Roubik, D.W., Hanson, P.E. (2004) Orchid bees of Tropical America, Biology and Field Guide. INBio Press, Santo Domingo de Heredia

Ruttner, F. (1988) Biogeography and Taxonomy of Honeybees. Springer Verlag, Berlin

Sheets, H.D. (2006) IMP Software. Dept. of Physics, Canisius College, Buffalo

Simmons, L.W., Tomkins, J.L., Alcock, J. (2000) Can minor males of Dawson's burrowing bee, Amegilla dawsoni (Hymenoptera: Anthophorini) compensate for reduced access to virgin females through sperm competition? Behav. Ecol. 11, 319-325

Zelditch, M.L., Swiderski, D.L., Sheets, H.D., Fink, W.L. (2004) Geometric Morphometrics for Biologists: A Primer. Elsevier Academic Press, London

Zera, A.J. (2004) The endocrine regulation of wing polymorphism in insects: state of the art, recent surprises, and future directions. Integr. Comp. Biol. 43, 607-616

Zinetti, F., Dapporto, L., Vanni, S., Magrini, P., Bartolozzi, L., Chelazzi, G., Ciofi, C. (2013) Application of molecular genetics and geometric morphometrics to taxonomy and conservation of cave beetles in central Italy. J. Insect Conserv. 17, 921-932 